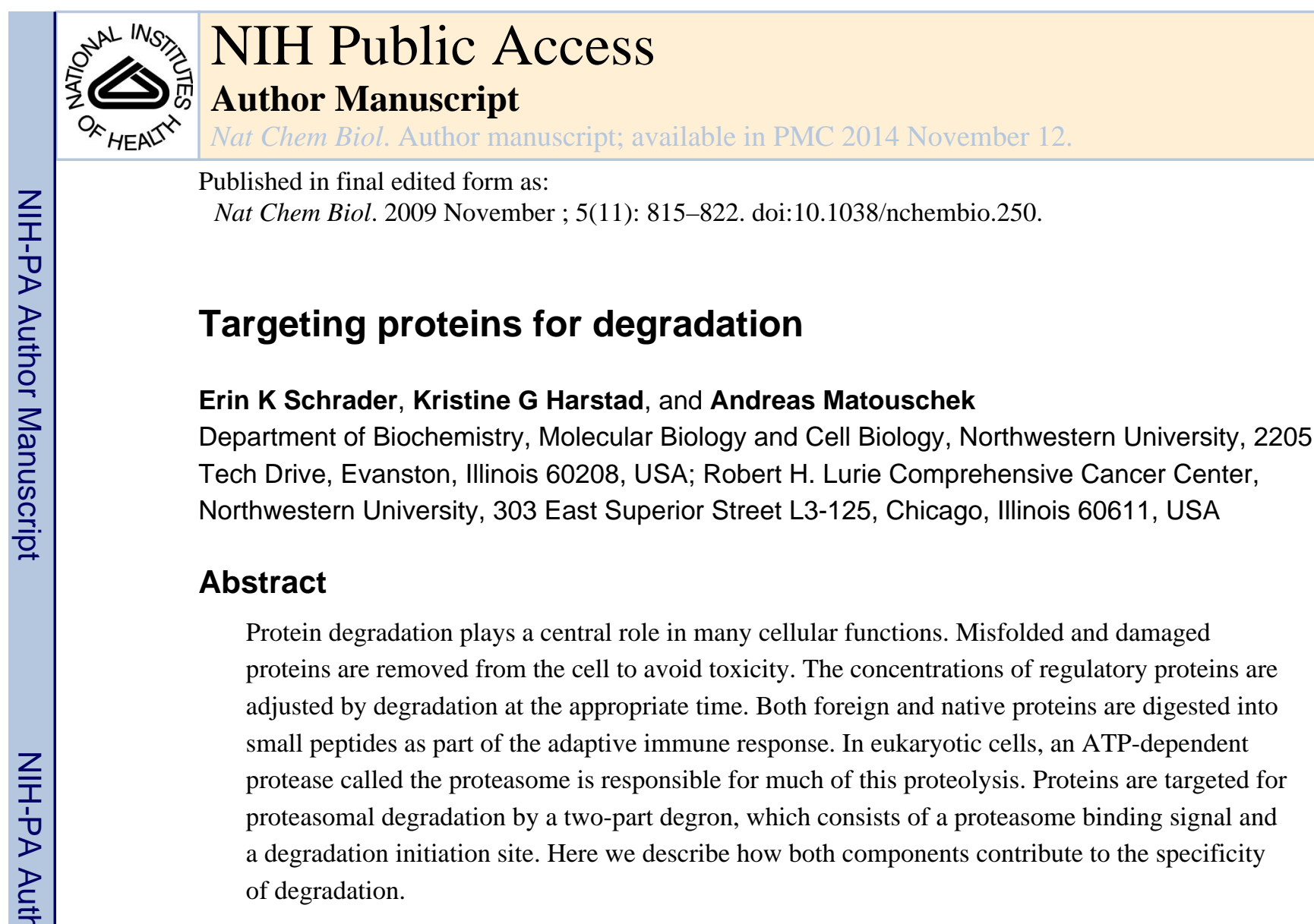

\title{
Introduction
}

The proteasome faces a challenge when selecting proteins to degrade. In the classical examples of substrate specificity, enzymes recognize a defined three-dimensional surface. For example, restriction enzymes and conventional proteases recognize specific nucleotide or amino acid sequences in the substrates they cleave. The proteasome, however, has to be able to digest hundreds of unrelated proteins and even foreign proteins the cell has not seen before. Therefore, it cannot have strong sequence preferences for its substrates. On the other hand, the proteasome is located in the cytosol and the nucleus, where it is exposed to the entire complement of cellular proteins. Therefore, it must be exquisitely specific and discriminatory to avoid reckless protein destruction.

The solution to this problem lies in the structure of the proteasome. The proteasome contains six proteolytic sites, which individually show weak sequence preferences in their substrates but together are able to degrade almost all proteins ${ }^{1}$. The cleavage sites are sequestered inside the proteasome, where they are inaccessible to most folded proteins. Only substrates that contain specific degradation signals, or degrons, are recognized by the proteasome, processively unfolded ${ }^{2}$, threaded into the degradation chamber, and digested. Thus, the proteasome controls access to the proteolytic sites. An overwhelming number of factors

matouschek@northwestern.edu

Competing financial interest statement

The authors declare that they have no competing interests as defined by Nature Publishing Group, or other interests that might be perceived to influence the results and/or discussion reported in this paper. 
affect how proteins are targeted to the proteasome. In this article, we will try to put these into a simple mechanistic framework.

\section{The proteasome}

The proteasome is a large cylindrical particle consisting of at least 33 subunits, with a total molecular weight of approximately $2.5 \mathrm{MDa}^{3,4}$. There are several variants of the proteasome that perform slightly different functions. For example, cells of the immune system contain a particular form of the proteasome that produces peptides for display at the cell surface ${ }^{5}$. We will focus on the version of the proteasome that is found in all cells and is responsible for the specific degradation of regulatory proteins and the removal of damaged proteins. This form, called the $26 \mathrm{~S}$ proteasome, is composed of a $20 \mathrm{~S}$ core particle capped by a $19 \mathrm{~S}$ regulatory particle ${ }^{3,4}$ at one or both ends (Fig. 1a). In bacteria, a series of ATP-dependent proteases share a common structural design with the proteasome and fulfill equivalent functions (Fig. 1b). The proteasome and these bacterial proteases are distantly related and belong to the group of AAA+ proteins (ATPases Associated with diverse cellular Activities).

The 20S core particle is a stack of four heptameric rings, which are assembled to form a cylindrical structure ${ }^{3}$. The outer two rings are made of a subunits, and the inner two rings are composed of $\beta$ subunits, which contain the proteolytic active sites in a central cavity (Fig. 1a). The degradation chamber can be reached through a channel that runs along the long axis of the core particle. The entrance to the channel is narrow, about $13 \AA^{6,7}$, such that folded proteins must be at least partially unfolded before they can be translocated into the $20 \mathrm{~S}$ core particle and degraded ${ }^{8}$.

The 19S regulatory particle is composed of at least 19 subunits arranged into two subcomplexes - the lid and the base. The regulatory particle contains ATPase subunits, gates the entrance to the degradation channel, and plays a role in substrate recognition, unfolding, and translocation into the 20S core particle ${ }^{4,5}$ (Fig. 1a).

\section{The degron}

The degron that leads to the degradation of a folded protein has two parts. Most proteins appear to be targeted for degradation by the covalent attachment of a tag that consists of several copies of the small protein ubiquitin ${ }^{9,10}$. However, ubiquitinated proteins are stable, at least in vitro, unless they also contain an unstructured region ${ }^{11}$, which is then the second component of the degron. The ubiquitin modification delivers the substrate to the proteasome and the unstructured region is the site at which degradation initiates ${ }^{11}$. Typically both parts of the degron are present in the same protein. However, the ubiquitin tag and initiation site also work when they are located on two distinct polypeptide chains that bind to each other to form a complex ${ }^{12}$.

\section{The ubiquitin tag}

Ubiquitin is attached to proteins by a series of three enzymatic activities. Individual ubiquitin molecules are activated by ubiquitin activating enzymes (E1s), transferred to 
ubiquitin conjugating enzymes (E2s) and from there to the substrate, which is recognized by ubiquitin protein-ligase enzymes (E3s), reviewed in ${ }^{10}$. Depending on the type of E3, the ubiquitin is either transferred from the E2 to the E3 and then to the substrate, or directly from the E2 to the substrate. Ubiquitin is almost always attached to the substrate through an isopeptide bond between the a-carboxyl group of the ubiquitin backbone and the $\varepsilon$-amino group of a lysine in the substrate. In a few rare cases ubiquitin has been found to be conjugated to $\mathrm{N}$-terminal residues ${ }^{13}$ or cysteines ${ }^{14}$. Oddly enough, the modification reaction does not usually stop after the first ubiquitin is attached to a protein but continues so that an additional ubiquitin moiety is attached to a lysine of the first ubiquitin, another ubiquitin is attached to this second one, and so on. At times, an additional enzyme, called an E4, is involved in this reaction, reviewed in $^{15}$. As a result, long ubiquitin chains form on substrates.

There are seven lysines in ubiquitin so polyubiquitin chains can form through different linkages, reviewed in ${ }^{16}$. In the classical view, the minimal signal necessary for proteasome targeting is a chain of four ubiquitin molecules linked through lysine 48 (K48) ${ }^{9}$. However, ubiquitin tags where the ubiquitin moieties are linked through other lysine residues such as $\mathrm{K} 11^{17}, \mathrm{~K} 63^{18,19}$, and probably others ${ }^{20}$ can also target proteins for proteasomal degradation. In a few cases, it appears that monoubiquitination is sufficient to target a protein for proteasome-mediated degradation ${ }^{21-23}$ but it is not clear if this targeting mode is widespread. Polyubiquitin chains linked through every lysine in ubiquitin are present in vivo in yeast ${ }^{20,24}$. Some of these polyubiquitin modifications, and the attachment of a single ubiquitin, have functions outside of degradation, such as in membrane trafficking ${ }^{25}$. Indeed, ubiquitination is emerging as a general and transferable protein-protein interaction signal, not unlike phosphorylation ${ }^{26}$.

\section{Delivery of ubiquitinated substrates to the proteasome}

Ubiquitinated proteins are delivered to the proteasome by various routes and the complete picture of how these pathways fit together has yet to emerge, reviewed in ${ }^{27}$. Some substrates bind directly to the proteasome by interacting with the 19S regulatory particle subunits Rpn $10^{28}$ or Rpn $13^{29}$, and probably Rpt5 ${ }^{30}$ (Fig. 2a). Alternatively, ubiquitinated substrates can be brought to the proteasome by adaptors that bind both the proteasome and the ubiquitin chain on the substrate to deliver it for degradation ${ }^{31-33}$ (Fig. 2b). Interestingly, a large proportion of Rpn10 is not associated with the proteasome and this population of Rpn10 may act much like the adaptor proteins discussed next. Lastly, some proteins are degraded by the proteasome but are not ubiquitinated (Fig. 2c); these proteins will be discussed later.

Three proteasome adaptor proteins, which appear to function in very similar ways, have been identified: $\operatorname{Rad} 23^{34-36}$, Dsk2 ${ }^{35,36}$, and Ddi $1^{36}$. All three of these contain a ubiquitinlike (UBL) domain that interacts with the proteasome and one or two ubiquitin-associated (UBA) domains that bind polyubiquitin chains ${ }^{36-38}$. The adaptors can bind the ubiquitinated substrate and proteasome simultaneously, and either guide the substrate directly to degradation by allowing the proteasome to engage the substrate at its initiation site, or by first handing the substrate off to ubiquitin-binding proteasome subunits ${ }^{5}$. It is not clear 
which substrates reach the proteasome directly and which flow through adaptors, although it has been suggested that proteins with long ubiquitin chains are more likely to take the direct path ${ }^{39}$. Genetic studies show that ubiquitin receptors can have overlapping functions and probably cooperate to degrade proteins ${ }^{33,40}$.

There may be yet other ways in which the proteasome can recognize ubiquitinated substrates. Proteasomal degradation is required for yeast to live, yet yeast strains in which all of the known ubiquitin receptors are inactivated are viable ${ }^{29}$, indicating that there may be other unidentified ubiquitin receptors. Some E3 ubiquitin-protein ligases bind to the proteasome ${ }^{27}$, in certain cases through UBL domains ${ }^{41}$. Of course, E3s also interact with substrates, so they may not only ubiquitinate their substrates but also deliver them to the proteasome, much like the previously mentioned adaptors ${ }^{27}$. E3 ligases can also mediate the binding of substrates to adaptor proteins ${ }^{27}$. For example, the adaptor Ddi1 interacts with the E3 ligase Ufo1, and Ddi1-Ufo1 binding is required for degradation of Ufo1's substrate ${ }^{42}$. The adaptor proteins and many associated proteins involved in protein targeting to the proteasome are present in both mammals and yeast ${ }^{27}$. Therefore, the overall targeting mechanism appears to be widely conserved.

\section{The ubiquitin modification is dynamic}

Although ubiquitin tags are an effective proteasome targeting signal, the conjugation of ubiquitin to proteins does not always lead to their degradation. One reason for this is that the ubiquitin modification can be very dynamic. Cells contain a large number of enzymes that remove ubiquitin chains from proteins and a few of these deubiquitinating enzymes are associated with or part of the proteasome, reviewed $\mathrm{in}^{43}$. One of them, a 19S subunit called Rpn11 in yeast, cleaves the entire ubiquitin chain off of proteins by hydrolyzing the isopeptide bond between the lysine in the substrate and the first ubiquitin moiety in the $\operatorname{tag}^{44,45}$. This cleavage occurs when the substrate is fully committed for degradation ${ }^{44}$ and allows the ubiquitin to escape from the proteasome and be recycled. In fact, protein degradation is impaired upon Rpn11 inactivation ${ }^{44,45}$ suggesting that polyubiquitin tags hinder substrate unfolding and/or translocation into the proteasome ${ }^{5}$.

Two other deubiquitinating enzymes associated with the proteasome, named Ubp6 and Uch37 in yeast, trim ubiquitin chains sequentially from the distal end ${ }^{46,47}$. This activity probably acts like a timer. When the ubiquitinated substrate is first bound, the proteasome tries to degrade the substrate but at the same time the ubiquitin tag begins to shrink. Eventually, the tag will be removed and if degradation has not yet initiated, the substrate will escape (Fig. 3a). Given that a chain of four K48-linked ubiquitin molecules binds to the proteasome with high affinity and longer ubiquitin chains have only slightly higher affinities ${ }^{9}$, it is likely that the purpose of longer ubiquitin chains is to enhance a substrate's resistance to deubiquitinating enzymes and thus increase the time a protein spends at the proteasome ${ }^{9,47}$. The activity of Ubp6 and Uch37 likely prevents degradation of lightly or improperly ubiquitinated protein substrates ${ }^{47,48}$. The deubiquitinating enzymes also prevent "clogging" of the proteasome. If a substrate spends too much time at the proteasome, potentially blocking other proteins from degradation, then the deubiquitinating enzymes will 
remove that protein's ubiquitin chain and promote the release of the indigestible substrate, thus preventing a backup.

However, the entire story is more complicated. A ubiquitin ligase with E4 activity, Hul5, is also associated with the proteasome and acts in opposition to the deubiquitinating enzymes ${ }^{48,49}$. That is, the previously mentioned "timer" is fine tuned by Hul5, which extends the ubiquitin chains on substrates, thereby increasing the time substrates spend at the proteasome and the likelihood of their degradation (Fig. 3b). In this way, the activities of both a ubiquitin ligase and deubiquitinating enzymes at the proteasome play a role in selecting substrates for proteasome-mediated degradation.

One example of how this ubiquitin "timer" could work comes from the mechanism by which degradation of cell cycle regulators is ordered in time. The E3 anaphase-promoting complex (APC) regulates cell cycle progression in mitosis and G1, reviewed in ${ }^{50}$. At the end of mitosis, the APC ubiquitinates a series of substrates to target them for degradation in a specific temporal order, which is known as substrate ordering. This substrate ordering depends on the processivity of ubiquitination by the APC ${ }^{51}$. The substrates that obtain their polyubiquitin chains in a single binding event to the APC are degraded first. The substrates that are degraded later require multiple APC binding events to become polyubiquitinated. Because these substrates bind to and dissociate from the APC repeatedly, they are more vulnerable to deubiquitinating enzymes. Thus, it seems that the proteins that receive their polyubiquitin chains first are also degraded earlier.

\section{The Cdc48 / p97 targeting machine}

Most ubiquitination and deubiquitination probably occurs away from the proteasome. Many E3 ubiquitin protein-ligases are soluble proteins by themselves or are bound to a small number of partners. However, enzymes that alter ubiquitin modifications can assemble into a large complex, which can function as a protein-targeting machine. A broad range of proteins, including E3 and E4 ligases, deubiquitinating enzymes, and ubiquitinated substrates assemble on $\mathrm{Cdc} 48^{52}$. Cdc48 (p97 in mammals) is an ATPase ring complex which is distantly related to the ATPases in the $19 \mathrm{~S}$ regulatory particle ${ }^{27}$. Cdc48 may determine the fate of a substrate by balancing or regulating its various associated enzymatic activities, reviewed in ${ }^{53}$. In one scenario, the Cdc48-associated ubiquitin ligases can lengthen the ubiquitin chain on the substrate. The ubiquitinated protein is then shuttled to the proteasome by the adaptor proteins Rad23 and Dsk2 and degraded ${ }^{39}$ (Fig. 4a). Alternatively, deubiquitinating enzymes recruited by $\mathrm{Cdc} 48$ can trim the ubiquitin chain and rescue the protein from proteolysis ${ }^{39,53}$ (Fig. 4b). The subunits of Cdc48 themselves are ATPases and it is possible that $\mathrm{Cdc} 48$ can unfold ubiquitinated proteins and facilitate proteasomal degradation by pre-denaturing substrates ${ }^{27}$.

Cdc48 clearly also has activities other than functioning as a binding platform for the ubiquitination machinery. It is one of the most abundant proteins in cells ${ }^{52}$ and is involved in many pathways, including endoplasmic reticulum (ER)-associated degradation and membrane fusion, reviewed in $27,52,53$. For example, Cdc48 removes ubiquitinated proteins from protein complexes, and extracts ubiquitinated substrates from membranes such as the 
ER membrane and then directs the extracted proteins to the proteasome $e^{54,55}$ as described above (Fig. 4a). During the last few years it has become clear that the Cdc48-proteasome pathway plays a much larger role in regulating protein turnover than previously thought ${ }^{52}$.

\section{Initiation of degradation}

Ubiquitin modification of a folded protein alone is not sufficient for its rapid degradation ${ }^{9,56,57}$. In addition to a proteasome targeting signal, a protein must contain a region for degradation initiation ${ }^{11,58}$. This initiation site is an unstructured region where the proteasome can engage the substrate and begin degradation. It can be at the end of a polypeptide chain ${ }^{11}$ or internal ${ }^{11,59,60}$ and flanked by folded domains on both sides ${ }^{11}$. In the simplest mechanism, the ubiquitin modification tethers a substrate to the proteasome and orients it so that the initiation site can be engaged by the proteasome's translocation motor. Based on studies of the bacterial analogues of the proteasome ${ }^{61-65}$, the motor is probably located in the ATPase ring of the $19 \mathrm{~S}$ regulatory particle ${ }^{66}$. Loops that protrude into the central pore of the ATPase ring most likely grab the unstructured initiation region and then pull on the substrate and cause unfolding and translocation ${ }^{62,66}$ (Fig. 1 and 3).

Proteins that lack an unstructured region can also be degraded because folded domains are in equilibrium with unfolded states. However, if unfolding fluctuations are rare or short-lived the ubiquitin modification may be removed before degradation initiates, and the substrate will dissociate from the proteasome before it is degraded.

\section{Requirements for an effective initiation site}

Unstructured regions are common in eukaryotic proteins. Therefore, the requirement for an initiation site is not likely to limit degradation of most proteasome substrates. However, there are situations where the initiation site seems to play a critical role in selecting substrates for degradation. Some proteins can bind to the proteasome or be heavily ubiquitinated, yet escape degradation. For example, the adaptor Rad23 binds to the proteasome $\mathrm{e}^{38}$ and delivers substrates for proteolysis, but itself remains stable $\mathrm{e}^{38,67}$. Perhaps $\operatorname{Rad} 23$ escapes destruction because the proteasome is unable to initiate its degradation. Interestingly, some of the proteins that avoid degradation contain disordered segments, suggesting that not all unstructured regions can promote degradation. There may be specific physical and chemical requirements for initiation sites. For example, they may have to be of a minimum length ${ }^{11,68}$ or be located in the substrate within a certain distance from the ubiquitin tag ${ }^{11}$. The amino acid composition and thus chemical properties of the unstructured region could also be important ${ }^{56,69}$.

\section{Trans initiation}

The two parts of the degron, the ubiquitin modification and the unstructured initiation site, can function together even when they are separated onto two polypeptide chains ${ }^{12}$. This observation is surprising, because the proteasome is able to select, extract, and degrade specific subunits from larger complexes while leaving the other subunits intact. This subunit-specificity of degradation was first described using model proteins ${ }^{70,71}$ and plays a critical role in many biological processes. For instance, as a cell moves through the cell 
cycle, cyclin-dependent kinases (cdks) are activated by cyclins at particular steps. For the cell to continue to progress through the cell cycle, the cdks have to be switched off again and this happens through the destruction of the cyclins. The cyclins become ubiquitinated ${ }^{72}$ and are degraded while complexed with the cdk, which itself remains intact ${ }^{72,73}$.

When the ubiquitin tag and the initiation site are separated onto different polypeptide chains ${ }^{12}$, it appears that the proteasome may degrade first the subunit with the most effective initiation site. This idea fits with some examples of subunit specificity. For instance, in the Cdk2-cyclin A complex, Cdk2 has a compact tertiary structure with no unfolded or disordered regions ${ }^{74}$. In contrast, the $\mathrm{N}$-terminus of cyclin $\mathrm{A}$ is mostly unstructured, contains the sites of ubiquitination, and is degraded ${ }^{72,75,76}$. Cdk2 may escape degradation simply because it lacks an effective initiation site for the proteasome.

However, in some instances the mechanism is not quite as obvious, such as in the case of the cell cycle regulator Sic1. Sic1 binds to a cdk-cyclin complex and inhibits its kinase activity. To activate the kinase, Sic1 has to be degraded and cdk-cyclin left intact, but both Sic1 and cyclin contain unstructured regions ${ }^{77}$ (Fig. 5a). The disordered region in Sic1 might be the more effective initiation site because it is closer to the ubiquitin tag. Once the ubiquitinated Sic1 is degraded, the rest of the complex would be safe from proteolysis until the cyclin becomes ubiquitinated in turn. There are some hints as to what physical and chemical factors affect initiation but clearly much work remains to be done to define the rules of initiation site selection ${ }^{11,56,68,69}$.

\section{Degradation without ubiquitin}

The observation of trans initiation suggests another interesting targeting mechanism: a ubiquitinated adaptor protein can shuttle many binding partners with initiation sites to the proteasome for degradation and itself remain stable $27,33,35,38$. This is the biochemical basis of the mechanism proposed for the Rad23, Dsk2, and Ddi1 adaptor proteins described above. This mechanism may also explain the degradation of some other proteins. For example, the antiretroviral cytidine deaminase APOBEC3G (A3G) is targeted for degradation by a viral infectivity factor (Vif). Vif has been shown to be polyubiquitinated, but a lysine-less A3G that cannot be ubiquitinated is still degraded ${ }^{78}$. This could be a case of trans targeting, in which the ubiquitinated Vif acts as an adaptor protein to bring A3G to the proteasome, where A3G would then be engaged through its initiation site $^{12}$ (Fig. 5b). Another example that may follow a similar mechanism is the human papillomavirus protein E7 and its binding partner, the retinoblastoma tumor suppressor protein $(\mathrm{Rb})$. It is known that $\mathrm{E} 7$ binds to and targets $\mathrm{Rb}$ for degradation ${ }^{79}$. $\mathrm{E} 7$ is ubiquitinated and binds to the proteasome ${ }^{80}$. Ubiquitinated $\mathrm{E} 7$ might act as an adaptor that targets $\mathrm{Rb}$ for degradation by trans initiation ${ }^{12}$.

An unstructured region in a protein might under some circumstances function as a proteasome initiation site by itself in the absence of ubiquitin (Fig. 2c). This could occur if the initiation site sequence has a particularly high affinity for the site on the proteasome that engages substrates, or when the proteasome and substrate are present at high concentrations so that even a weak interaction leads to substrate binding. 
Indeed, ubiquitin is not always required to target proteins for proteasomal degradation, reviewed in ${ }^{81-84}$. The original and best-understood example of ubiquitin-independent proteasomal degradation is ornithine decarboxylase (ODC $)^{85}$. ODC is a folded protein yet it can be degraded efficiently in the absence of ubiquitin by the full proteasome particle in the canonical ATP-dependent process ${ }^{85}$. This degradation requires the protein antizyme 1 (AZ1), which binds to ODC but itself escapes proteolysis ${ }^{86}$ (Fig. 2c). AZ1 increases the association of ODC with the proteasome ${ }^{86}$. AZ1 binding exposes a 37 amino acid region in the $\mathrm{C}$-terminus of $\mathrm{ODC}^{86}$ from which degradation begins ${ }^{87}$. Thus, ODC may be degraded because its initiation site has a particularly high affinity for the proteasome, or because AZ1 functions like an adaptor protein.

There are several additional proteins that may be degraded in the absence of ubiquitin (e.g., p $21^{\mathrm{CIP} 1}$, p53, c-Jun, IkBa, thymidylate synthase, $\mathrm{T}$ cell antigen receptor chain $\mathrm{a}$, Fra-1, and Hif-1a, reviewed in $\left.{ }^{81-84}\right)$. In many cases, the evidence for ubiquitin-independent degradation was obtained in vitro, so that the physiological relevance of this degradation is unclear. In fact, the physiological degradation of some of these proteins depends strongly on ubiquitin. Nevertheless, unstructured proteins can be degraded by the $20 \mathrm{~S}$ core particle in a ubiquitin- and ATP-independent manner, reviewed in $^{83}$. Although it is not known what forms of the proteasome exist and in what proportion in vivo, some singly-capped or uncapped $20 \mathrm{~S}$ core particles are likely present. At the same time, purified $26 \mathrm{~S}$ proteasomes are able to cleave some proteins that are not ubiquitinated at internal disordered regions, leaving the structured domains intact ${ }^{88}$.

In summary, ubiquitin-independent degradation, in the context of the two-part degron model, could be explained by the fact that the unstructured regions within the proteins could function as particularly effective initiation sites. Alternatively, the proteins could be degraded because they are shuttled to the proteasome by adaptors or ubiquitinated binding partners.

\section{Parallels with bacterial degrons}

In bacteria, regulated protein degradation is carried out by ATP-dependent proteases such as ClpAP, ClpXP, Lon, HslUV, and FtsH, reviewed in ${ }^{89-91}$. These bacterial proteases share a common structural design with the eukaryotic proteasome (Fig. 1b). Some bacteria even use a ubiquitin-like modifier to tag proteins for degradation ${ }^{92,93}$. This modifier is a 64 amino acid protein found in Mycobacterium tuberculosis called prokaryotic ubiquitin-like protein or Pup ${ }^{92}$. Like ubiquitin, Pup targets proteins to a proteasome-like particle ${ }^{92,93}$. A broad range of proteins appear to be modified by Pup ${ }^{92,93}$ and Pup is present in all major actinobacteria and a few other bacterial lineages ${ }^{94}$. However, most bacteria do not use a ubiquitin-like degradation tag and at first glance, the mechanisms by which proteins are targeted for degradation in eukaryotes, bacteria, and archaea appear to be quite different. But like in eukaryotes, bacterial degrons have two functions: they target proteins to the protease and serve as the initiation site for degradation ${ }^{90}$.

Proteins are targeted for degradation in bacteria by signals in their primary amino acid sequence, often near the $\mathrm{N}$ - or C-terminus ${ }^{95}$, reviewed in ${ }^{90}$. Degradation begins at these 
degrons and they are therefore in some ways equivalent to the unstructured regions that serve as degradation initiation sites in proteasome substrates. In one particularly intriguing case, the degron is not encoded in the same gene as the substrate protein but is appended during translation by a switch of the template RNA. The switch leads to the synthesis of an 11 amino acid long tail at the $\mathrm{C}$-terminus of the nascent protein and release from the ribosome ${ }^{96}$. The ssrA tag targets proteins for degradation by several proteases ${ }^{90}$. Most other bacterial degrons are not well characterized ${ }^{89}$.

In eukaryotes, the substrate is in most cases tethered to the proteasome by the ubiquitin tag. In bacteria, this function can often be performed by the linear degradation signal itself. There are perhaps a few cases where two distinct sequences in a substrate could perform the protease binding and initiation functions ${ }^{97,98}$. However, parallels with the eukaryotic targeting mechanism are clearest in the use of bacterial adaptor proteins in degradation, reviewed in ${ }^{89,90}$.

For three bacterial adaptors, it is quite well understood how they regulate protein degradation and deliver proteins to proteases, reviewed in ${ }^{89,90}$. One example is $\mathrm{SspB}$, which targets the majority of ssrA-tagged proteins for degradation ${ }^{99}$ by linking the protein directly to the protease ${ }^{100}$. Like eukaryotic adaptor proteins, SspB functions as a shuttle ${ }^{27}$. The substrate is degraded and $\mathrm{SspB}$ remains stable ${ }^{90}$, allowing it to recapture additional proteins for destruction. Sometimes adaptor proteins themselves are regulated. For example, the activity of the adaptor RssB, which controls the $\sigma^{\mathrm{S}}$ subunit of RNA polymerase, is mediated by several anti-adaptors ${ }^{101-103}$.

The adaptor protein ClpS is responsible for $\mathrm{N}$-end rule ${ }^{104,105}$ degradation in bacteria ${ }^{106}$. The $\mathrm{N}$-end rule relates the stability of a protein with the identity of its $\mathrm{N}$-terminal amino acid, called the $\mathrm{N}$-degron ${ }^{104,105}$. ClpS recognizes the $\mathrm{N}$-degron ${ }^{106}$ as well as $\mathrm{ClpA}^{107}$ and shuttles the protein for degradation ${ }^{106}$. The $\mathrm{N}$-end rule also functions in eukaryotes, where proteins with $\mathrm{N}$-degrons are recognized and ubiquitinated by E3 ligases called N-recognins, reviewed in ${ }^{108}$. The domains in ClpS and the $\mathrm{N}$-recognins that recognize the $\mathrm{N}$-degrons are homologous ${ }^{109-111}$ showing that the $\mathrm{N}$-end rule pathway is conserved between eukaryotes and bacteria even if the mechanistic details by which it functions are very different ${ }^{108}$.

\section{The unfolding ability of proteases}

The fact that bacteria contain different ATP-dependent proteases allows a variation in the mechanism of substrate selection that is absent in eukaryotes. It appears that bacterial ATPdependent proteases differ greatly in their ability to unfold substrate proteins ${ }^{112}$. Some proteins might contain degrons that are recognized by a protease, but if the protease lacks the ability to unfold the substrates, they escape. Thus, information is found in both the targeting signal and in the stability of the folded domains of the substrates ${ }^{112}$. The unfolding ability of the eukaryotic proteasome is greater than that of the bacterial proteases so under most circumstances proteins are unable to resist degradation. However, it is possible to stabilize some proteins by ligand binding such that they resist even the eukaryotic proteasome ${ }^{8}$. In addition, some protein aggregates that form as part of disease processes may be too stable to be denatured and degraded by the proteasome ${ }^{113,114}$. 


\section{Practical applications}

The principles that govern protein targeting to the proteasome can be exploited to control protein degradation artificially and several methods have been developed to manipulate protein stability, reviewed in ${ }^{115}$. For example, fusion of a target protein to ODC can destabilize the protein and its binding partners ${ }^{116}$. ODC degradation is ubiquitinindependent so this method does not require ubiquitination for target protein degradation.

Other artificial degradation systems use inducible dimerization domains derived from FKBP and FRB. Both of these domains bind the naturally-occurring small molecule rapamycin such that the addition of rapamycin will cause any two fusion proteins containing these domains to dimerize ${ }^{117,118}$. Perhaps the most direct implementation of this system has been developed in yeast ${ }^{119}$, where a proteasome subunit is tagged with the FKBP domain and the FRB domain is fused to the target protein. On addition of rapamycin, the FRB and FKBP domains dimerize and the target protein becomes bound to the proteasome, where it is then degraded ${ }^{119}$. Like the ODC-fusion method, this system causes degradation of the target protein without ubiquitination.

In a method used to create conditional alleles, a target protein is destabilized by fusing it to a modified FRB or FKBP domain. The altered FRB or FKBP domains act as degrons, most likely because they contain mutations that cause partial unfolding ${ }^{120,121}$. The target protein can then be stabilized by rapamycin-induced binding of endogenous FKBP to the FRB degron, or small molecule ligand binding to the FKBP degron. In another method, called Split Ubiquitin for Rescue of Function or SURF ${ }^{122}$, the target protein is released completely unmodified following stabilization. Here several FRB domains and half of the ubiquitin coding sequence are fused to the N-terminus of the target protein, which leads to its rapid degradation. The other half of ubiquitin is fused to FKBP. When rapamycin addition causes the dimerization of FRB and FKBP, the two halves of ubiquitin are brought together and form a complete ubiquitin molecule. The reconstituted ubiquitin is then recognized by cellular enzymes that cleave the ubiquitin and FRB domains off the target protein, which is released in its native form.

Another method manipulates the ubiquitin-conjugation machinery itself to artificially target specific proteins for degradation. A protein-binding domain can be fused to an E2 so that the E2 ubiquitinates the protein that is brought into its vicinity ${ }^{123}$. Similarly, some E3s can be redirected to new targets when their substrate recognition subunits are modified to recognize a specific target ${ }^{124,125}$. Another possibility is to bring the $\mathrm{E} 3$ to a substrate with a bifunctional ligand that recognizes both the $\mathrm{E} 3$ and the target protein ${ }^{126}$. These ligands have been called Proteolysis-targeting chimeric molecules or Protacs, and several cell-permeable ligands for different proteins are effective in cell culture ${ }^{127}$.

Lastly, the $\mathrm{N}$-end rule can be used to manipulate the stability of target proteins in yeast. Fusion with a short peptide that leads to the display of a destabilizing N-terminal residue can greatly decrease the half-life of a target protein ${ }^{128}$. Further, if a destabilizing N-terminal residue is masked in a heat labile protein domain, $\mathrm{N}$-end rule degradation can be made 
temperature-dependent. Degradation of a protein fused to this domain can then be induced by increasing the temperature ${ }^{129}$.

\section{Conclusion}

In summary, we propose that the great complexity of mechanisms by which proteins are targeted for degradation by ATP-dependent proteases can be explained by a simple chemical mechanism. The degron contains two parts: a tether that allows the protease to grab the substrate, and an initiation site where degradation begins. In eukaryotes the tether is usually formed by a reversibly-attached ubiquitin tag, and degradation initiates at an unstructured region in the substrate. However, there are many variations on this theme. For example, sometimes the substrate is recognized through adaptor proteins that bind the substrate and proteasome at the same time. It is possible that the initiation site by itself may be sufficient to target proteins for degradation in some cases. In bacteria, it is common for substrates to be recognized by their initiation sites alone but adaptors that recognize the substrate and protease also play an important role. Covalently attached tags seem to be rarer in bacteria but at least two examples exist ${ }^{92,93,96}$. Thus, eukaryotes and bacteria appear to have similarly solved the problem of how to utilize a proteolytic process that can hydrolyze nearly all proteins in a controlled and specific manner. Protein targeting and degradation apparently follow the same overall principle in bacteria and in eukaryotes ${ }^{90}$.

\section{Acknowledgments}

We thank members of the Matouschek lab for advice and comments. The work was supported by grant R01GM64003 from the US National Institutes of Health, by grant MCB 426913 from the National Science Foundation, and by the Robert H. Lurie Comprehensive Cancer Center at Northwestern University. E. S. was supported by the Oncogenesis and Developmental Biology training grant T32 CA080621 from the US National Institutes of Health.

\section{References}

1. Nussbaum AK, et al. Cleavage motifs of the yeast 20S proteasome $\beta$ subunits deduced from digests of enolase 1. Proc Natl Acad Sci U S A. 1998; 95:12504-12509. [PubMed: 9770515]

2. Lee C, Schwartz MP, Prakash S, Iwakura M, Matouschek A. ATP-Dependent Proteases Degrade Their Substrates by Processively Unraveling Them from the Degradation Signal. Mol Cell. 2001; 7:627-637. [PubMed: 11463387]

3. Groll M, et al. Structure of 20 S proteasome from yeast at 2.4 Å resolution. Nature. $1997 ; 386: 463-$ 471. [PubMed: 9087403]

4. Tanaka K. The proteasome: overview of structure and functions. Proc Jpn Acad Ser B Phys Biol Sci. 2009; 85:12-36.

5. Finley D. Recognition and Processing of Ubiquitin-Protein Conjugates by the Proteasome. Annu Rev Biochem. 2009; 78:477-513. [PubMed: 19489727]

6. Lowe J, et al. Crystal structure of the $20 \mathrm{~S}$ proteasome from the archaeon T. acidophilum at $3.4 \AA$ resolution. Science. 1995; 268:533-539. [PubMed: 7725097]

7. Groll M, et al. A gated channel into the proteasome core particle. Nat Struct Biol. 2000; 7:10621067. [PubMed: 11062564]

8. Johnston JA, Johnson ES, Waller PRH, Varshavsky A. Methotrexate Inhibits Proteolysis of Dihydrofolate Reductase by the N-end Rule Pathway. J Biol Chem. 1995; 270:8172-8178. [PubMed: 7713922]

9. Thrower JS, Hoffman L, Rechsteiner M, Pickart CM. Recognition of the polyubiquitin proteolytic signal. EMBO J. 2000; 19:94-102. [PubMed: 10619848] 
10. Weissman AM. Themes and variations on ubiquitylation. Nat Rev Mol Cell Biol. 2001; 2:169178. [PubMed: 11265246]

11. Prakash S, Tian L, Ratliff KS, Lehotzky RE, Matouschek A. An unstructured initiation site is required for efficient proteasome-mediated degradation. Nat Struct Mol Biol. 2004; 11:830-837. [PubMed: 15311270]

12. Prakash S, Inobe T, Hatch AJ, Matouschek A. Substrate selection by the proteasome during degradation of protein complexes. Nat Chem Biol. 2009; 5:29-36. [PubMed: 19029916]

13. Ciechanover A, Ben-Saadon R. N-terminal ubiquitination: more protein substrates join in. Trends Cell Biol. 2004; 14:103-106. [PubMed: 15055197]

14. Cadwell K, Coscoy L. Ubiquitination on nonlysine residues by a viral E3 ubiquitin ligase. Science. 2005; 309:127-130. [PubMed: 15994556]

15. Hoppe T. Multiubiquitylation by E4 enzymes: “one size' doesn't fit all. Trends Biochem Sci. 2005; 30:183-187. [PubMed: 15817394]

16. Pickart CM, Fushman D. Polyubiquitin chains: polymeric protein signals. Curr Opin Chem Biol. 2004; 8:610-616. [PubMed: 15556404]

17. Jin L, Williamson A, Banerjee S, Philipp I, Rape M. Mechanism of Ubiquitin-Chain Formation by the Human Anaphase-Promoting Complex. Cell. 2008; 133:653-665. [PubMed: 18485873]

18. Hofmann RM, Pickart CM. In Vitro Assembly and Recognition of Lys-63 Polyubiquitin Chains. J Biol Chem. 2001; 276:27936-27943. [PubMed: 11369780]

19. Saeki Y, et al. Lysine 63-linked polyubiquitin chain may serve as a targeting signal for the $26 \mathrm{~S}$ proteasome. EMBO J. 2009; 28:359-371. [PubMed: 19153599]

20. Xu P, et al. Quantitative proteomics reveals the function of unconventional ubiquitin chains in proteasomal degradation. Cell. 2009; 137:133-145. [PubMed: 19345192]

21. Shaeffer JR, Kania MA. Degradation of monoubiquitinated a-globin by $26 \mathrm{~S}$ proteasomes. Biochemistry. 1995; 34:4015-4021. [PubMed: 7696267]

22. Boutet SC, Disatnik M-H, Chan LS, Iori K, Rando TA. Regulation of Pax3 by Proteasomal Degradation of Monoubiquitinated Protein in Skeletal Muscle Progenitors. Cell. 2007; 130:349_ 362. [PubMed: 17662948]

23. Kravtsova-Ivantsiv Y, Cohen S, Ciechanover A. Modification by single ubiquitin moieties rather than polyubiquitination is sufficient for proteasomal processing of the $\mathrm{p} 105 \mathrm{NF}-\kappa \mathrm{B}$ precursor. Mol Cell. 2009; 33:496-504. [PubMed: 19250910]

24. Peng $\mathbf{J}$, et al. A proteomics approach to understanding protein ubiquitination. Nat Biotechnol. 2003; 21:921-926. [PubMed: 12872131]

25. Hicke L, Riezman H. Ubiquitination of a yeast plasma membrane receptor signals its ligandstimulated endocytosis. Cell. 1996; 84:277-287. [PubMed: 8565073]

26. Hicke L, Schubert HL, Hill CP. Ubiquitin-binding domains. Nat Rev Mol Cell Biol. 2005; 6:610621. [PubMed: 16064137]

27. Elsasser S, Finley D. Delivery of ubiquitinated substrates to protein-unfolding machines. Nat Cell Biol. 2005; 7:742-749. [PubMed: 16056265]

28. Deveraux Q, Ustrell V, Pickart C, Rechsteiner M. A 26 S protease subunit that binds ubiquitin conjugates. J Biol Chem. 1994; 269:7059-7061. [PubMed: 8125911]

29. Husnjak K, et al. Proteasome subunit Rpn13 is a novel ubiquitin receptor. Nature. 2008; 453:481488. [PubMed: 18497817]

30. Lam YA, Lawson TG, Velayutham M, Zweier JL, Pickart CM. A proteasomal ATPase subunit recognizes the polyubiquitin degradation signal. Nature. 2002; 416:763-767. [PubMed: 11961560]

31. Elsasser S, Chandler-Militello D, Muller B, Hanna J, Finley D. Rad23 and Rpn10 serve as alternative ubiquitin receptors for the proteasome. J Biol Chem. 2004; 279:26817-26822. [PubMed: 15117949]

32. Kim I, Mi K, Rao H. Multiple interactions of rad23 suggest a mechanism for ubiquitylated substrate delivery important in proteolysis. Mol Biol Cell. 2004; 15:3357-3365. [PubMed: 15121879] 
33. Verma R, Oania R, Graumann J, Deshaies RJ. Multiubiquitin Chain Receptors Define a Layer of Substrate Selectivity in the Ubiquitin-Proteasome System. Cell. 2004; 118:99-110. [PubMed: 15242647]

34. Chen L, Madura K. Rad23 promotes the targeting of proteolytic substrates to the proteasome. Mol Cell Biol. 2002; 22:4902-4913. [PubMed: 12052895]

35. Rao H, Sastry A. Recognition of specific ubiquitin conjugates is important for the proteolytic functions of the ubiquitin-associated domain proteins Dsk2 and Rad23. J Biol Chem. 2002; 277:11691-11695. [PubMed: 11805121]

36. Wilkinson CR, et al. Proteins containing the UBA domain are able to bind to multi-ubiquitin chains. Nat Cell Biol. 2001; 3:939-943. [PubMed: 11584278]

37. Hiyama H, et al. Interaction of hHR23 with S5a. The ubiquitin-like domain of hHR23 mediates interaction with S5a subunit of 26 S proteasome. J Biol Chem. 1999; 274:28019-28025. [PubMed: 10488153]

38. Schauber C, et al. Rad23 links DNA repair to the ubiquitin/proteasome pathway. Nature. 1998; 391:715-718. [PubMed: 9490418]

39. Richly H, et al. A series of ubiquitin binding factors connects CDC48/p97 to substrate multiubiquitylation and proteasomal targeting. Cell. 2005; 120:73-84. [PubMed: 15652483]

40. Madura K. Rad23 and Rpn10: perennial wallflowers join the melee. Trends Biochem Sci. 2004; 29:637-640. [PubMed: 15544949]

41. Sakata E, et al. Parkin binds the Rpn10 subunit of 26 S proteasomes through its ubiquitin-like domain. EMBO Rep. 2003; 4:301-306. [PubMed: 12634850]

42. Kaplun L, et al. The DNA damage-inducible UbL-UbA protein Ddi1 participates in Mec1mediated degradation of Ho endonuclease. Mol Cell Biol. 2005; 25:5355-5362. [PubMed: 15964793]

43. Amerik AY, Hochstrasser M. Mechanism and function of deubiquitinating enzymes. Biochim Biophys Acta. 2004; 1695:189-207. [PubMed: 15571815]

44. Verma R, et al. Role of Rpn11 Metalloprotease in Deubiquitination and Degradation by the $26 \mathrm{~S}$ Proteasome. Science. 2002; 298:611-615. [PubMed: 12183636]

45. Yao T, Cohen RE. A cryptic protease couples deubiquitination and degradation by the proteasome. Nature. 2002; 419:403-407. [PubMed: 12353037]

46. Hanna J, et al. Deubiquitinating enzyme Ubp6 functions noncatalytically to delay proteasomal degradation. Cell. 2006; 127:99-111. [PubMed: 17018280]

47. Lam YA, Xu W, DeMartino GN, Cohen RE. Editing of ubiquitin conjugates by an isopeptidase in the 26S proteasome. Nature. 1997; 385:737-740. [PubMed: 9034192]

48. Crosas B, et al. Ubiquitin Chains Are Remodeled at the Proteasome by Opposing Ubiquitin Ligase and Deubiquitinating Activities. Cell. 2006; 127:1401-1413. [PubMed: 17190603]

49. Kraut DA, Prakash S, Matouschek A. To degrade or release: ubiquitin-chain remodeling. Trends Cell Biol. 2007; 17:419-421. [PubMed: 17900906]

50. Peters JM. The anaphase-promoting complex: proteolysis in mitosis and beyond. Mol Cell. 2002; 9:931-943. [PubMed: 12049731]

51. Rape M, Reddy SK, Kirschner MW. The Processivity of Multiubiquitination by the APC Determines the Order of Substrate Degradation. Cell. 2006; 124:89-103. [PubMed: 16413484]

52. Ye Y. Diverse functions with a common regulator: ubiquitin takes command of an AAA ATPase. J Struct Biol. 2006; 156:29-40. [PubMed: 16529947]

53. Jentsch S, Rumpf S. Cdc48 (p97): a "molecular gearbox“ in the ubiquitin pathway? Trends Biochem Sci. 2007; 32:6-11. [PubMed: 17142044]

54. Jarosch E, et al. Protein dislocation from the ER requires polyubiquitination and the AAA-ATPase Cdc48. Nat Cell Biol. 2002; 4:134-139. [PubMed: 11813000]

55. Ye Y, Meyer HH, Rapoport TA. The AAA ATPase Cdc48/p97 and its partners transport proteins from the ER into the cytosol. Nature. 2001; 414:652-656. [PubMed: 11740563]

56. Bachmair A, Varshavsky A. The degradation signal in a short-lived protein. Cell. 1989; 56:10191032. [PubMed: 2538246] 
57. Petroski MD, Deshaies RJ. Context of multiubiquitin chain attachment influences the rate of Sic1 degradation. Mol Cell. 2003; 11:1435-1444. [PubMed: 12820958]

58. Takeuchi J, Chen H, Coffino P. Proteasome substrate degradation requires association plus extended peptide. EMBO J. 2007; 26:123-131. [PubMed: 17170706]

59. Liu CW, Corboy MJ, DeMartino GN, Thomas PJ. Endoproteolytic activity of the proteasome. Science. 2003; 299:408-411. [PubMed: 12481023]

60. Piwko W, Jentsch S. Proteasome-mediated protein processing by bidirectional degradation initiated from an internal site. Nat Struct Mol Biol. 2006; 13:691-697. [PubMed: 16845392]

61. Hinnerwisch J, Fenton WA, Furtak KJ, Farr GW, Horwich AL. Loops in the central channel of ClpA chaperone mediate protein binding, unfolding, and translocation. Cell. 2005; 121:1029_ 1041. [PubMed: 15989953]

62. Martin A, Baker TA, Sauer RT. Pore loops of the AAA+ ClpX machine grip substrates to drive translocation and unfolding. Nat Struct Mol Biol. 2008; 15:1147-1151. [PubMed: 18931677]

63. Park E, et al. Role of the GYVG pore motif of HslU ATPase in protein unfolding and translocation for degradation by HslV peptidase. J Biol Chem. 2005; 280:22892-22898. [PubMed: 15849200]

64. Yamada-Inagawa T, Okuno T, Karata K, Yamanaka K, Ogura T. Conserved pore residues in the AAA protease FtsH are important for proteolysis and its coupling to ATP hydrolysis. J Biol Chem. 2003; 278:50182-50187. [PubMed: 14514680]

65. Wang J, et al. Nucleotide-dependent conformational changes in a protease-associated ATPase HsIU. Structure. 2001; 9:1107-1116. [PubMed: 11709174]

66. Wang J, et al. Crystal structures of the HslVU peptidase-ATPase complex reveal an ATPdependent proteolysis mechanism. Structure. 2001; 9:177-184. [PubMed: 11250202]

67. Heessen S, Masucci MG, Dantuma NP. The UBA2 domain functions as an intrinsic stabilization signal that protects Rad23 from proteasomal degradation. Mol Cell. 2005; 18:225-235. [PubMed: 15837425]

68. Verhoef LG, et al. Minimal length requirement for proteasomal degradation of ubiquitin-dependent substrates. FASEB J. 2009; 23:123-133. [PubMed: 18796559]

69. Tian L, Holmgren RA, Matouschek A. A conserved processing mechanism regulates the activity of transcription factors Cubitus interruptus and NF- $\kappa$ B. Nat Struct Mol Biol. 2005; 12:1045-1053. [PubMed: 16299518]

70. Johnson ES, Gonda DK, Varshavsky A. Cis-trans recognition and subunit-specific degradation of short-lived proteins. Nature. 1990; 346:287-291. [PubMed: 2165217]

71. Hochstrasser M, Varshavsky A. In vivo degradation of a transcriptional regulator: the yeast a2 repressor. Cell. 1990; 61:697-708. [PubMed: 2111732]

72. King RW, Deshaies RJ, Peters JM, Kirschner MW. How proteolysis drives the cell cycle. Science. 1996; 274:1652-1659. [PubMed: 8939846]

73. Nishiyama A, et al. A nonproteolytic function of the proteasome is required for the dissociation of Cdc2 and cyclin B at the end of M phase. Genes Dev. 2000; 14:2344-2357. [PubMed: 10995390]

74. Jeffrey PD, et al. Mechanism of CDK activation revealed by the structure of a cyclinA-CDK2 complex. Nature. 1995; 376:313-320. [PubMed: 7630397]

75. King RW, Glotzer M, Kirschner MW. Mutagenic analysis of the destruction signal of mitotic cyclins and structural characterization of ubiquitinated intermediates. Mol Biol Cell. 1996; 7:1343-1357. [PubMed: 8885231]

76. Klotzbucher A, Stewart E, Harrison D, Hunt T. The "destruction box' of cyclin A allows B-type cyclins to be ubiquitinated, but not efficiently destroyed. EMBO J. 1996; 15:3053-3064. [PubMed: 8670806]

77. Verma R, McDonald H, Yates JR 3rd, Deshaies RJ. Selective degradation of ubiquitinated Sic1 by purified 26S proteasome yields active S phase cyclin-Cdk. Mol Cell. 2001; 8:439-448. [PubMed: 11545745]

78. Dang Y, Siew LM, Zheng YH. APOBEC3G is degraded by the proteasomal pathway in a Vifdependent manner without being polyubiquitylated. J Biol Chem. 2008; 283:13124-13131. [PubMed: 18326044] 
79. Gonzalez SL, Stremlau M, He X, Basile JR, Munger K. Degradation of the retinoblastoma tumor suppressor by the human papillomavirus type $16 \mathrm{E} 7$ oncoprotein is important for functional inactivation and is separable from proteasomal degradation of E7. J Virol. 2001; 75:7583-7591. [PubMed: 11462030]

80. Berezutskaya E, Bagchi S. The human papillomavirus E7 oncoprotein functionally interacts with the S4 subunit of the 26 S proteasome. J Biol Chem. 1997; 272:30135-30140. [PubMed: 9374493]

81. Hoyt MA, Coffino P. Ubiquitin-free routes into the proteasome. Cell Mol Life Sci. 2004; 61:15961600. [PubMed: 15224184]

82. Jariel-Encontre I, Bossis G, Piechaczyk M. Ubiquitin-independent degradation of proteins by the proteasome. Biochim Biophys Acta. 2008; 1786:153-177. [PubMed: 18558098]

83. Orlowski M, Wilk S. Ubiquitin-independent proteolytic functions of the proteasome. Arch Biochem Biophys. 2003; 415:1-5. [PubMed: 12801506]

84. Verma R, Deshaies RJ. A Proteasome Howdunit: The Case of the Missing Signal. Cell. 2000; 101:341-344. [PubMed: 10830160]

85. Murakami Y, et al. Ornithine decarboxylase is degraded by the $26 \mathrm{~S}$ proteasome without ubiquitination. Nature. 1992; 360:597-599. [PubMed: 1334232]

86. Zhang M, Pickart CM, Coffino P. Determinants of proteasome recognition of ornithine decarboxylase, a ubiquitin-independent substrate. EMBO J. 2003; 22:1488-1496. [PubMed: 12660156]

87. Zhang M, MacDonald AI, Hoyt MA, Coffino P. Proteasomes Begin Ornithine Decarboxylase Digestion at the C Terminus. J Biol Chem. 2004; 279:20959-20965. [PubMed: 15016805]

88. Baugh JM, Viktorova EG, Pilipenko EV. Proteasomes Can Degrade a Significant Proportion of Cellular Proteins Independent of Ubiquitination. J Mol Biol. 2009; 386:814-827. [PubMed: 19162040]

89. Baker TA, Sauer RT. ATP-dependent proteases of bacteria: recognition logic and operating principles. Trends Biochem Sci. 2006; 31:647-653. [PubMed: 17074491]

90. Sauer RT, et al. Sculpting the proteome with AAA(+) proteases and disassembly machines. Cell. 2004; 119:9-18. [PubMed: 15454077]

91. Striebel F, Kress W, Weber-Ban E. Controlled destruction: AAA+ ATPases in protein degradation from bacteria to eukaryotes. Curr Opin Struct Biol. 2009; 19:209-217. [PubMed: 19362814]

92. Pearce MJ, Mintseris J, Ferreyra J, Gygi SP, Darwin KH. Ubiquitin-like protein involved in the proteasome pathway of Mycobacterium tuberculosis. Science. 2008; 322:1104-1107. [PubMed: 18832610]

93. Burns KE, Liu WT, Boshoff HI, Dorrestein PC, Barry CE 3rd. Proteasomal protein degradation in Mycobacteria is dependent upon a prokaryotic ubiquitin-like protein. J Biol Chem. 2009; 284:3069-3075. [PubMed: 19028679]

94. Iyer L, Burroughs AM, Aravind L. Unraveling the biochemistry and provenance of pupylation: a prokaryotic analog of ubiquitination. Biol Direct. 2008; 3:45. [PubMed: 18980670]

95. Flynn JM, Neher SB, Kim YI, Sauer RT, Baker TA. Proteomic discovery of cellular substrates of the ClpXP protease reveals five classes of ClpX-recognition signals. Mol Cell. 2003; 11:671-683. [PubMed: 12667450]

96. Keiler KC, Waller PR, Sauer RT. Role of a peptide tagging system in degradation of proteins synthesized from damaged messenger RNA. Science. 1996; 271:990-993. [PubMed: 8584937]

97. Hoskins JR, Wickner S. Two peptide sequences can function cooperatively to facilitate binding and unfolding by ClpA and degradation by ClpAP. Proc Natl Acad Sci U S A. 2006; 103:909-14. [PubMed: 16410355]

98. Ninnis RL, Spall SK, Talbo GH, Truscott KN, Dougan DA. Modification of PATase by L/Ftransferase generates a ClpS-dependent N-end rule substrate in Escherichia coli. EMBO J. 2009; 28:1732-1744. [PubMed: 19440203]

99. Levchenko I, Seidel M, Sauer RT, Baker TA. A Specificity-Enhancing Factor for the ClpXP Degradation Machine. Science. 2000; 289:2354-2356. [PubMed: 11009422]

100. Dougan DA, Weber-Ban E, Bukau B. Targeted Delivery of an ssrA-Tagged Substrate by the Adaptor Protein SspB to Its Cognate AAA+ Protein ClpX. Mol Cell. 2003; 12:373-380. [PubMed: 14536077] 
101. Muffler A, Fischer D, Altuvia S, Storz G, Hengge-Aronis R. The response regulator RssB controls stability of the $\sigma(\mathrm{S})$ subunit of RNA polymerase in Escherichia coli. EMBO J. 1996; 15:1333-1339. [PubMed: 8635466]

102. Zhou Y, Gottesman S, Hoskins JR, Maurizi MR, Wickner S. The RssB response regulator directly targets sigma(S) for degradation by ClpXP. Genes Dev. 2001; 15:627-637. [PubMed: 11238382]

103. Bougdour A, Wickner S, Gottesman S. Modulating RssB activity: IraP, a novel regulator of sigma(S) stability in Escherichia coli. Genes Dev. 2006; 20:884-897. [PubMed: 16600914]

104. Bachmair A, Finley D, Varshavsky A. In vivo half-life of a protein is a function of its aminoterminal residue. Science. 1986; 234:179-186. [PubMed: 3018930]

105. Tobias JW, Shrader TE, Rocap G, Varshavsky A. The N-end rule in bacteria. Science. 1991; 254:1374-1377. [PubMed: 1962196]

106. Erbse A, et al. ClpS is an essential component of the N-end rule pathway in Escherichia coli. Nature. 2006; 439:753-756. [PubMed: 16467841]

107. Dougan DA, Reid BG, Horwich AL, Bukau B. ClpS, a Substrate Modulator of the ClpAP Machine. Mol Cell. 2002; 9:673-683. [PubMed: 11931773]

108. Mogk A, Schmidt R, Bukau B. The N-end rule pathway for regulated proteolysis: prokaryotic and eukaryotic strategies. Trends Cell Biol. 2007; 17:165-172. [PubMed: 17306546]

109. Wang KH, Roman-Hernandez G, Grant RA, Sauer RT, Baker TA. The Molecular Basis of N-End Rule Recognition. Mol Cell. 2008; 32:406-414. [PubMed: 18995838]

110. Lupas AN, Koretke KK. Bioinformatic analysis of ClpS, a protein module involved in prokaryotic and eukaryotic protein degradation. J Struct Biol. 2003; 141:77-83. [PubMed: 12576022]

111. Schuenemann VJ, et al. Structural basis of N-end rule substrate recognition in Escherichia coli by the ClpAP adaptor protein ClpS. EMBO Rep. 2009; 10:508-514. [PubMed: 19373253]

112. Koodathingal P, et al. ATP-dependent Proteases Differ Substantially in Their Ability to Unfold Globular Proteins. J Biol Chem. 2009; 284:18674-18684. [PubMed: 19383601]

113. Bence NF, Sampat RM, Kopito RR. Impairment of the Ubiquitin-Proteasome System by Protein Aggregation. Science. 2001; 292:1552-1555. [PubMed: 11375494]

114. Kaganovich D, Kopito R, Frydman J. Misfolded proteins partition between two distinct quality control compartments. Nature. 2008; 454:1088-1095. [PubMed: 18756251]

115. Banaszynski LA, Wandless TJ. Conditional control of protein function. Chem Biol. 2006; 13:1121. [PubMed: 16426967]

116. Matsuzawa S, Cuddy M, Fukushima T, Reed JC. Method for targeting protein destruction by using a ubiquitin-independent, proteasome-mediated degradation pathway. Proc Natl Acad Sci U S A. 2005; 102:14982-14987. [PubMed: 16219697]

117. Spencer DM, Wandless TJ, Schreiber SL, Crabtree GR. Controlling signal transduction with synthetic ligands. Science. 1993; 262:1019-1024. [PubMed: 7694365]

118. Liberles SD, Diver ST, Austin DJ, Schreiber SL. Inducible gene expression and protein translocation using nontoxic ligands identified by a mammalian three-hybrid screen. Proc Natl Acad Sci U S A. 1997; 94:7825-7830. [PubMed: 9223271]

119. Janse DM, Crosas B, Finley D, Church GM. Localization to the Proteasome Is Sufficient for Degradation. J Biol Chem. 2004; 279:21415-21420. [PubMed: 15039430]

120. Stankunas K, et al. Conditional Protein Alleles Using Knockin Mice and a Chemical Inducer of Dimerization. Mol Cell. 2003; 12:1615-1624. [PubMed: 14690613]

121. Banaszynski LA, Chen L.-c. Maynard-Smith LA, Ooi AGL, Wandless TJ. A Rapid, Reversible, and Tunable Method to Regulate Protein Function in Living Cells Using Synthetic Small Molecules. Cell. 2006; 126:995-1004. [PubMed: 16959577]

122. Pratt MR, Schwartz EC, Muir TW. Small-molecule-mediated rescue of protein function by an inducible proteolytic shunt. Proc Natl Acad Sci U S A. 2007; 104:11209-11214. [PubMed: 17563385]

123. Gosink MM, Vierstra RD. Redirecting the specificity of ubiquitination by modifying ubiquitinconjugating enzymes. Proc Natl Acad Sci U S A. 1995; 92:9117-9121. [PubMed: 7568084] 
124. Zhou P, Bogacki R, McReynolds L, Howley PM. Harnessing the ubiquitination machinery to target the degradation of specific cellular proteins. Mol Cell. 2000; 6:751-756. [PubMed: 11030355]

125. Su Y, Ishikawa S, Kojima M, Liu B. Eradication of pathogenic $\beta$-catenin by Skp1/Cullin/F box ubiquitination machinery. Proc Natl Acad Sci U S A. 2003; 100:12729-12734. [PubMed: 14563921]

126. Sakamoto KM, et al. Protacs: chimeric molecules that target proteins to the Skp1-Cullin-F box complex for ubiquitination and degradation. Proc Natl Acad Sci U S A. 2001; 98:8554-8559. [PubMed: 11438690]

127. Schneekloth JS, et al. Chemical Genetic Control of Protein Levels: Selective in Vivo Targeted Degradation. J Am Chem Soc. 2004; 126:3748-3754. [PubMed: 15038727]

128. Park EC, Finley D, Szostak JW. A strategy for the generation of conditional mutations by protein destabilization. Proc Natl Acad Sci U S A. 1992; 89:1249-1252. [PubMed: 1311090]

129. Dohmen RJ, Wu P, Varshavsky A. Heat-inducible degron: a method for constructing temperature-sensitive mutants. Science. 1994; 263:1273-1276. [PubMed: 8122109] 


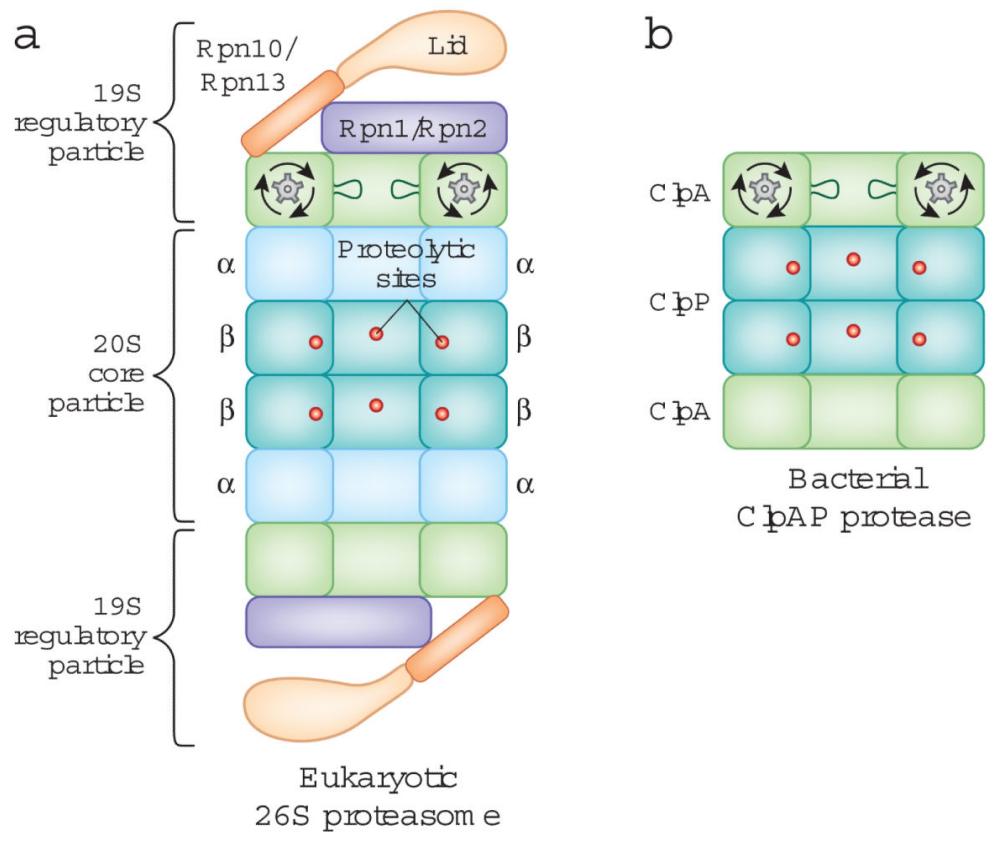

Figure 1.

The overall structure of the eukaryotic proteasome and the bacterial ClpAP protease.

The two proteases have a common architecture. The protease sites are buried in an internal chamber of the core particle, which is capped by regulatory particles that control access to the proteolytic chamber and contain an ATPase hexameric ring.

A: Side-on cross-section of the eukaryotic $26 \mathrm{~S}$ proteasome. The $20 \mathrm{~S}$ core particle is flanked by $19 \mathrm{~S}$ regulatory particles, and the proteolytic sites are located in the $\beta$-rings of the $20 \mathrm{~S}$ core particle. The scaffold proteins Rpn1 and Rpn2, the ubiquitin receptors Rpn10 and Rpn13, and the loops lining the ATPase ring are depicted. Only one set of loops is shown for clarity.

B: Side-on cross-section of the ClpAP protease from Escherichia coli. ClpP contains the proteolytic sites and is capped on both ends by the ClpA ATPase ring. 


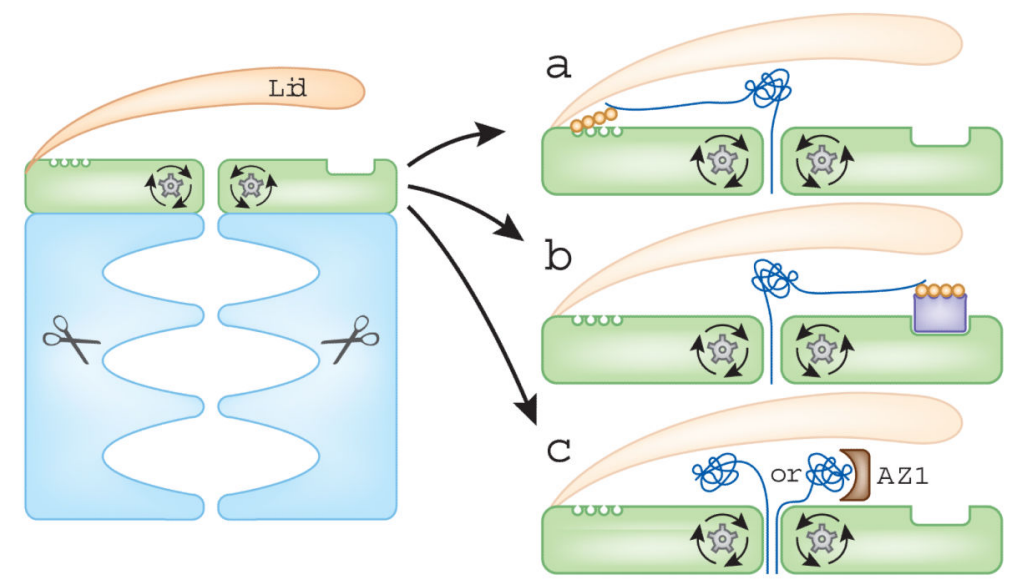

Figure 2.

Mechanisms of targeting ubiquitinated proteins to the proteasome.

A: Some substrates bind directly to the 19 S regulatory particle subunits Rpn10 or Rpn13.

B: Ubiquitinated substrates can also be carried to the proteasome by adaptor proteins, which bind both to the ubiquitin modification of the substrate and to the proteasome.

C: Several proteins are targeted to the proteasome independent of ubiquitination. Two cases are shown. On the left, a protein is engaged by the proteasome in the absence of any separate proteasome-binding motif. This might occur if the initiation site has a particularly high affinity for the site on the proteasome that engages substrates. On the right, ornithine decarboxylase (ODC) is shown as it is degraded by the proteasome when bound to antizyme 1 (AZ1). AZ1 binding to ODC exposes a 37 amino acid proteasome recognition signal in the C-terminus of ODC, where degradation then begins. The 37 amino acid signal may function as a high affinity proteasome binding site by itself, or AZ1 may act like an adaptor protein. 

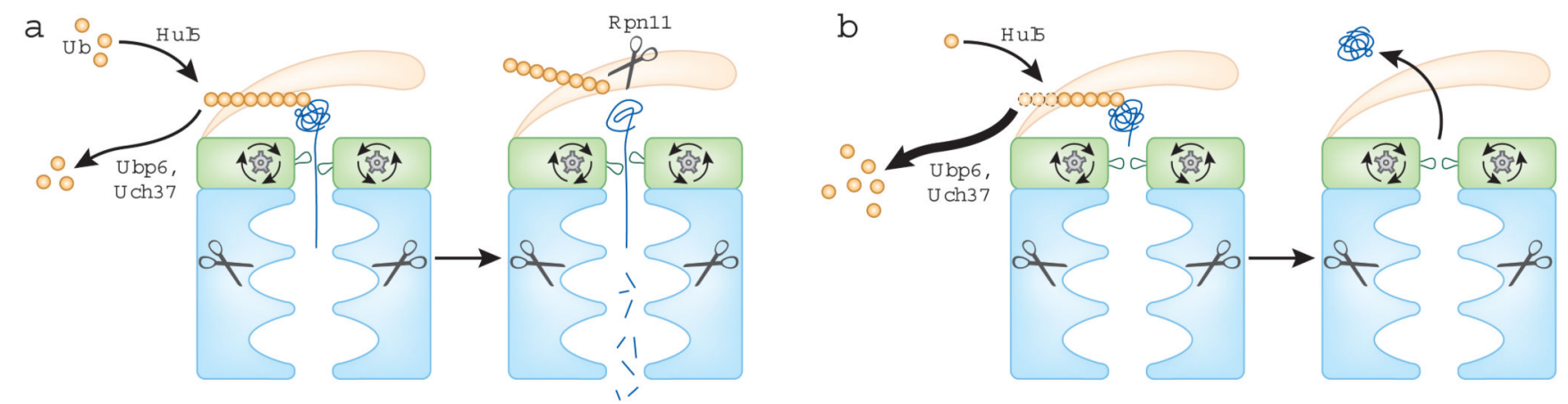

Figure 3.

An initiation site is required for protein degradation.

A: A protein lacking an initiation site escapes degradation.

The proteasome-targeted protein does not have an effective initiation site. The deubiquitinating enzymes trim the ubiquitin chain before the proteasome engages the substrate fully and initiates degradation. Thus, the intact substrate is released from the proteasome.

B: A protein containing an effective initiation site is degraded by the proteasome.

A ubiquitinated protein is recognized by the proteasome, and the ubiquitin ligase Hul5 and the deubiquitinating enzymes Ubp6 and Uch37 extend or trim the ubiquitin chain, respectively. The proteasome engages the protein at its unstructured region, which leads to unfolding and translocation of the polypeptide into the degradation chamber. In this case, the proteasome engages the substrate so rapidly that the deubiquitinating enzymes are not able to remove enough ubiquitin moieties to cause substrate release. 

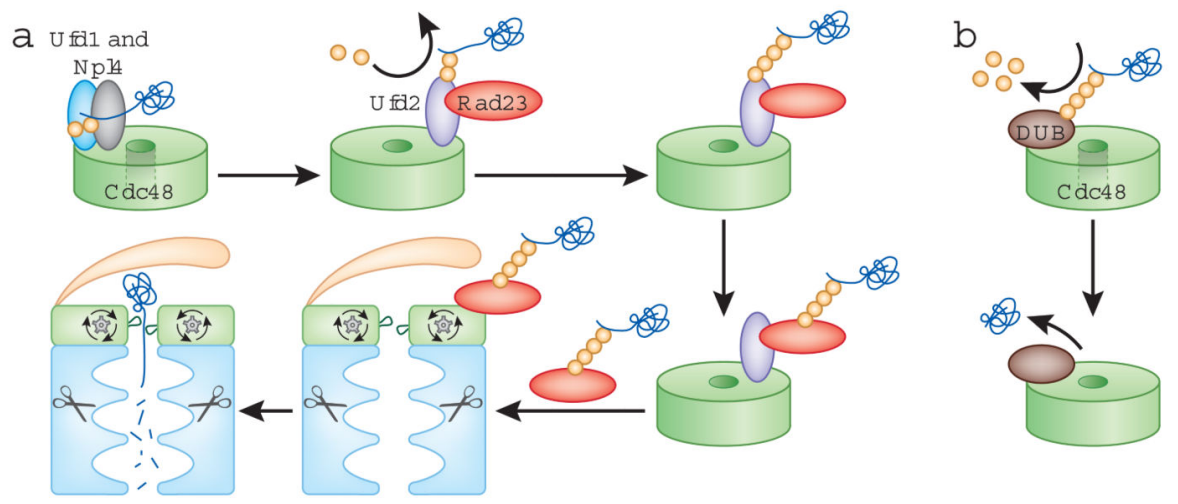

Figure 4.

The Cdc48 / p97 targeting machine.

$\mathrm{Cdc} 48$ / p97 is an ATPase ring complex involved in a range of cellular processes. It can serve as a scaffold for the assembly of E3 and E4 ligases, deubiquitinating enzymes, and ubiquitinated substrates. The fate of a substrate may be determined by the various enzymatic activities associated with $\mathrm{Cdc} 48$.

A: The Ufd1-Npl4 heterodimer recruits a polyubiquitinated substrate to Cdc48. The polyubiquitin chain on the substrate is lengthened by Ufd2, which has E4 activity. The substrate is then passed from Ufd2 to the adaptor protein Rad23 (or Dsk2), which shuttles the protein to the proteasome for degradation. Figure adapted from ${ }^{39}$.

B: Cdc48-associated deubiquitinating enzymes (DUBs), such as Otu1, can trim the polyubiquitin chain on a substrate and prevent its degradation. 

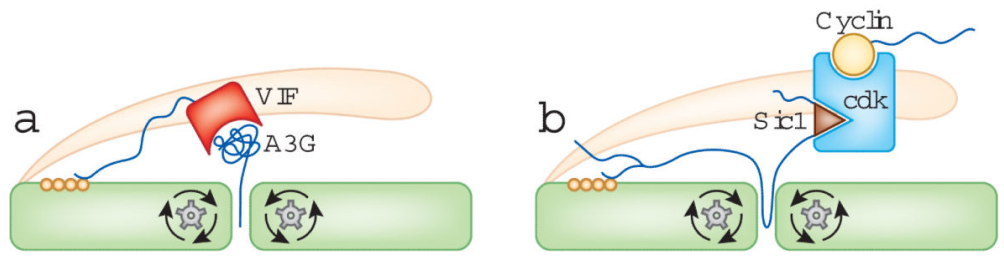

Figure 5.

Degradation of specific subunits from larger complexes.

A: The cell cycle regulator Sic1 binds to a cyclin dependent kinase (cdk)-cyclin complex and inhibits its activity. During the cell cycle, Sic1 is degraded in a process that leaves cdkcyclin intact despite the fact that both Sic1 and cyclin contain unstructured regions that can serve as initiation sites. Sic1 could be degraded first because its disordered region is a more effective initiation site in this complex.

B: Viral infectivity factor (Vif) targets the antiretroviral cytidine deaminase APOBEC3G (A3G) for degradation. Polyubiquitinated Vif can mediate the degradation of lysine-less A3G that cannot be ubiquitinated. This could occur by trans targeting, where the ubiquitinated Vif acts as an adaptor protein to bring A3G to the proteasome. Degradation begins when $\mathrm{A} 3 \mathrm{G}$ is engaged by the proteasome at its initiation site. 